\title{
Rainfall variability in Northern Tanzania in the March-May season (long rains) and its links to large-scale climate forcing
}

\author{
Eduardo Zorita ${ }^{1, *}$, Faustine F. Tilya ${ }^{2}$ \\ ${ }^{1}$ Institute for Coastal Research, GKSS-Forschungszentrum, Max-Planck-Str. 1, 21502 Geesthacht, Germany \\ ${ }^{2}$ Tanzania Meteorological Agency, PO Box 3056, Dar-es-Salaam, Tanzania
}

\begin{abstract}
Mean rainfall in Northern Tanzania is characterized by 2 annual maxima: in March-May, the long rains, and in October-December, the short rains. The interannual variability of rainfall in the March-May season and its relationships to large-scale fields from the NCEP/NCAR Reanalysis in the African-Indian Ocean sector were analysed. It was found that the March-May precipitation has characteristics different to that in October-December, the former being much less persistent within the season and being associated with intraseasonally changing large-scale patterns of surface temperature, sea-level pressure and winds. March and April rainfall anomalies are linked to zonal thermal contrast between the Indian Ocean and the Eastern African land mass, to zonal surface winds anomalies and to vertical velocity anomalies. On the other hand, May rainfall anomalies are associated with a meridional surface temperature contrast between the Indian Ocean and the Asian continent and meridional surface winds anomalies, indicating a relationship to the Indian Monsoon. Local convergence seems to play a smaller role than for March anomalies. Indeed, Northern Tanzanian rainfall anomalies in May are correlated with the area-averaged Indian rainfall in the following months of June, July and August. The consequences for possible statistical seasonal prediction schemes are briefly discussed.
\end{abstract}

KEY WORDS: Rainfall · Eastern Africa $\cdot$ Indian Ocean $\cdot$ Monsoon

\section{INTRODUCTION}

It is generally recognised that the climate dynamics in the Indian Ocean region is not as well understood as that of its counterparts, the Tropical Pacific and Tropical Atlantic regions. In the latter oceans modes of coupled ocean-atmosphere variability have been identified, and in the case of the Pacific Ocean this understanding has led to successful prediction schemes of climate anomalies in the adjacent land masses based on statistical and dynamical models. These efforts will probably lead to operational medium-term climate forecasts for regions with economic activities very much dependent on the external seasonal climatic conditions (Kerr 1998). The situation in the Indian Ocean is much less satisfactory. Efforts to predict rainfall associ-

*E-mail: zorita@gkss.de ated with the Indian Monsoon are not so well developed (Hastenrath et al. 1993, Clark et al. 2000) and its interactions with the El Niño-Southern Oscillation (ENSO) phenomenon are still unclear (Meehl 1997). Recently, a coupled ocean-atmosphere mode of variability in the Indian Ocean seems to have been identified that, according to some authors, is largely independent of the Indian Monsoon and the ENSO (Saji et al. 1999, Webster et al. 1999), but may involve dynamics similar to the ENSO. Other authors, however, have presented evidence of a coupling to the ENSO (Mutai \& Ward 2000). The time scales involved are shorter than in the Pacific Ocean, since the ocean basin is smaller. This Indian Ocean coupled mode is also seasonally locked, starting with zonal wind anomalies near Indonesia around June and leading to fully developed sea-surface temperatures (SST) in the Western Indian Ocean in September-October. Associated with 


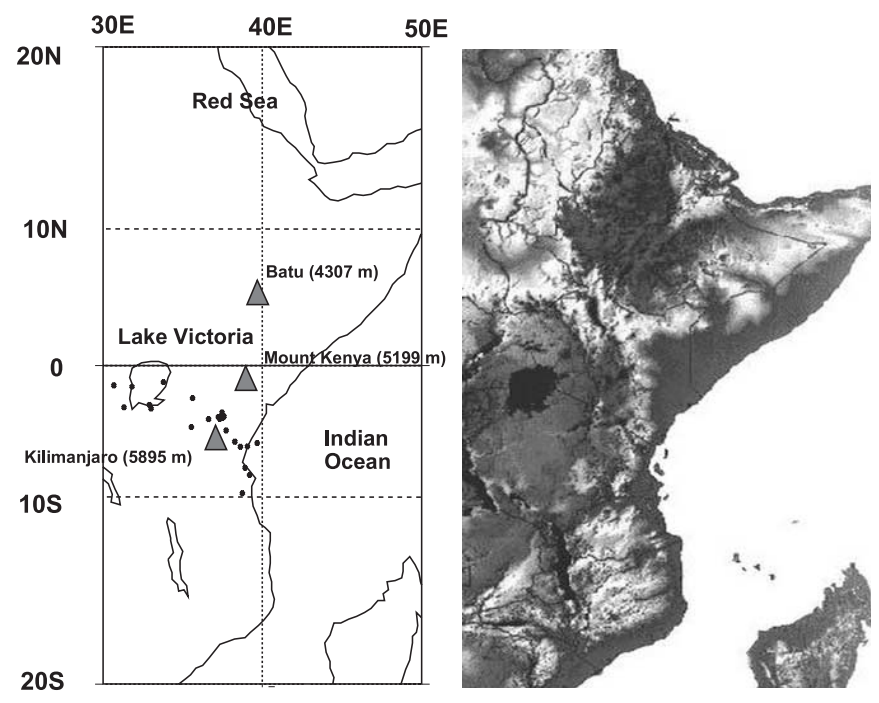

Fig. 1. Location of the rainfall stations used in this study (see also Table 1) and a topographical map of East Africa

these SST anomalies are precipitation anomalies in East Africa (Webster et al. 1999). Therefore, precipitation anomalies in equatorial Eastern Africa in October-December are thought to be part of a coherent large-scale variability in the whole Indian Ocean.

The space-time structure of Eastern African rainfall is fairly complicated. Stations located in Northern Tanzania (along the coast, in the Northern Highlands and around Lake Victoria, see Fig. 1) exhibit an annual bimodal rainfall distribution, with maxima in the March-May and October-December seasons. They are known as the long rains and short rains seasons, respectively. This bimodality is absent for the stations located in Southern, Central and Western Tanzania, where only 1 maximum in October-April is observed. The interannual rainfall variability in the OctoberDecember season and its connections to the largescale climate forcing have been recently investigated by Kabanda \& Jury (1999), who found some associations with the ENSO phenomenon and the Quasi-biennial Oscillation. As mentioned before, other authors (Webster et al. 1999, Clark et al. 2000) include Eastern African rainfall variability in this season in the framework of a proper large-scale oscillation in the Indian Ocean.

In contrast to the October-December season, precipitation anomalies in the March-May season have attracted less attention. Significantly, the March-May precipitation is only briefly discussed in the otherwise comprehensive paper by Hastenrath et al. (1993) on eastern African rainfall. In the present paper an analysis of the structure of the March-May precipitation in Northern Tanzania is attempted. The goal is to clarify its relationship to the large-scale climate anomalies in the Indian Ocean region, towards the long-term goal of exploring the possibilities of a statistical prediction scheme. For this purpose, full use is made of the global meteorological reanalysis from the National Center for Environmental Prediction (NCEP/NCAR), a valuable tool that has recently become available.

\section{DATA AND METHODS}

The rainfall data consist of monthly rainfall totals from 22 stations from Northern Tanzania, with the best data coverage for a period of 36 yr (1963-1998). Fig. 1 and Table 1 indicate the location of the stations. They are situated within a geographical box extending between 1 and $8^{\circ} \mathrm{S}$ and between 30 and $40^{\circ} \mathrm{E}$. The data were obtained from the Tanzania Meteorological Agency. Gaps in the time series were filled in using double-mass curves and information from the nearest stations.

This area of study has a variety of important orographic features (Fig. 1). Lake Victoria is the largest lake in the tropics. The coast and northeastern areas are characterised by almost continuous north-south highland grounds, peaking at Mount Kilimanjaro (about $6000 \mathrm{~m}$ ). This elevated groundwork parallels the coast bounded by the Indian Ocean to the east. North of the equator, the Ethiopian High Lands reach heights of about $4000 \mathrm{~m}$.

As a source for large-scale climate data we have used monthly means of sea-level pressure (SLP); air

Table 1. Position of the Northern Tanzanian stations. See also Fig. 1

\begin{tabular}{|lcc|}
\hline Station & Longitude $\left(^{\circ}\right)$ & Latitude $\left(^{\circ}\right)$ \\
\hline Ukiriguru & 33.02 & -2.75 \\
Karume & 39.07 & -5.08 \\
Same & 37.73 & -4.08 \\
Rombo & 37.73 & -4.08 \\
Mwanza & 32.92 & -2.47 \\
Musoma & 33.8 & -1.5 \\
Moshi & 37.33 & -3.35 \\
Mbulu & 35.55 & -3.87 \\
Lyamungu & 37.25 & -3.23 \\
Lushoto & 38.28 & -4.78 \\
Loliondo & 35.62 & -2.05 \\
Kilema & 37.50 & -3.30 \\
Kigomashi & 39.68 & -4.87 \\
Engare & 37.48 & -2.95 \\
Dia & 39.20 & -6.87 \\
Bukoba & 31.82 & -1.33 \\
Biharamulo & 31.32 & -2.63 \\
Bagamoyo & 38.92 & -6.42 \\
Arusha & 36.63 & -3.37 \\
Amani & 38.63 & -5.10 \\
Kaisho & 30.68 & -1.25 \\
Utete & 38.75 & -8.02 \\
\hline
\end{tabular}


temperature, zonal and meridional wind components near the surface (0.995 sigma level); vertical velocity at $850 \mathrm{mb}$ height; and winds at $200 \mathrm{mb}$ height from the NCEP/NCAR Reanalysis (Kalnay et al. 1996). For some calculations also the reanalysed rainfall was compared with the station data available. The area selected for the large-scale atmospheric fields is $0-120^{\circ} \mathrm{E}$, $40^{\circ} \mathrm{S}-40^{\circ} \mathrm{N}$. This area covers the African continent and most of the Indian Ocean. At earlier stages of the work larger windows were used that included the Tropical Atlantic and the Tropical Pacific. However no stable signal was found in this region, and therefore the 2 tropical ocean regions were deleted in the final figures.

The near-surface air temperature data over the ocean are used in this study as a closely related proxy to SST. The air temperature data were preferred in this study to other publicly available SST data sets, such as COADS, since the latter show a great amount of missing data in the early part of the record in the Indian Ocean. In addition, the use of air temperature has proven to be advantageous at some points in the analysis. The temperature anomaly patterns associated with Tanzanian rainfall show in some cases consistent patterns over the continents that are quite helpful in the interpretations of the results (for instance, in the case of the link between May rainfall and the Indian Monsoon, see Section 3). Furthermore, the air-temperature patterns for the months of October through December (see Section 3) agree quite well with the SST patterns obtained by other authors (Mutai \& Ward 2000).

Essentially, 2 statistical methods were used: empirical orthogonal function (EOF) analysis of the precipitation data and correlation of the resulting principal components onto the large-scale fields from the NCEP/ NCAR reanalysis. In the EOF analysis (von Storch \& Zwiers 1999) the time-dependent deviations from the long-term mean are decomposed into a sum of products of fixed spatial patterns $p_{k}$ and time-dependent amplitudes $\alpha_{k}$ (the principal components), as follows:

$$
f\left(x_{i}, t\right)=\sum_{k} p\left(x_{i}\right) \alpha_{i}(t)
$$

where the principal components, $\alpha_{k}$, are uncorrelated to one another and describe subsequently a maximum of variance in the original anomaly field, $f$. Under these conditions the EOFs, $p_{k}$, are the eigenvectors of the covariance matrix of $f$. The normalization of the patterns $p_{k}$ is arbitrary, and once it is chosen it determines the normalization of the time series $\alpha_{k}$. A normalization was chosen in which the standard deviation of $\alpha_{k}$ is unity, and therefore the spatial patterns $p_{k}$ indicate the typical magnitudes of the anomalies associated with the EOF $k$.
The large-scale climate anomalies of a field $g$ associated with EOF $k$ are estimated by calculating the point-by-point correlation between the anomaly field and the principal component $k$ as follows:

$$
\hat{g}\left(x_{i}\right)=\sum_{t} \frac{g\left(x_{i}, t\right) \alpha_{k}(t)}{\sqrt{\sum g^{2}\left(x_{i}, t\right)}}
$$

\section{MONTHLY PRECIPITATION VARIABILITY IN NORTHERN TANZANIA}

The annual cycle of monthly precipitation in Northern Tanzania presents 2 maxima, in the March-May and October-December seasons, due to the passage of the Intertropical Convergence Zone (Fig. 2). The March-May (hereafter MM) precipitation is in the mean more intense than the October-December (OD) precipitation, but it is proportionally less variable. Fig. 2 also shows the interannnual standard deviation of precipitation for each month of the year.

Recently, some deficiencies of the reanalysed rainfall in the NCEP Reanalysis over Tropical Africa have been described (Poccard et al. 2000). These authors found that in general the NCEP Reanalyses underestimate the observed rainfall, especially in the regions with a double-maximum annual cycle, such as Northern Tanzania. Fig. 2 also shows the annual cycle of the monthly rainfall and of its interannual standard deviation in the NCEP/NCAR Reanalysis for the grid point situated at $37.5^{\circ} \mathrm{E}, 1.9^{\circ} \mathrm{S}$. The observed mean rainfall and the standard deviation are underestimated by about a factor 2 over the whole year, but the form of the annual cycle is quite well represented. Therefore, the deficiencies indicated by Poccard et al. (2000) are also confirmed for the Northern Tanzanian region. Perhaps more important for the present analysis is the time correlation between the reanalysed rainfall and the station data. Since rainfall data are not assimilated in the reanalyses (Janowiak et al. 1998), a reasonable corre-
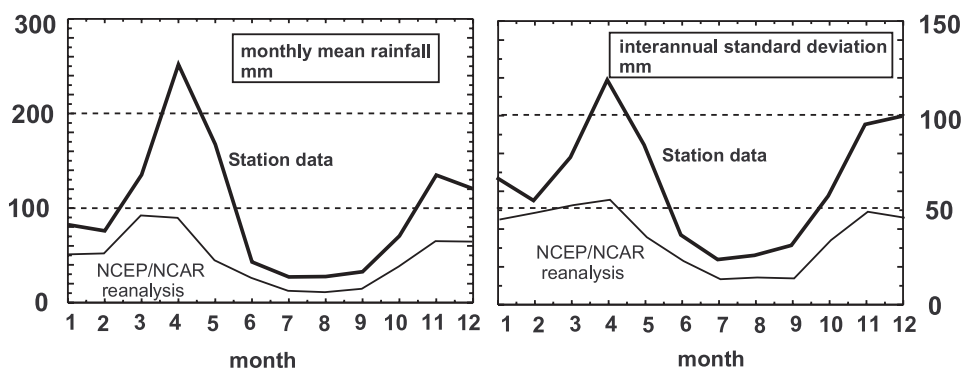

Fig. 2. Monthly mean rainfall and interannual standard deviation of rainfall averaged over the Northern Tanzanian stations. Also shown are the corresponding statistics of the NCEP/NCAR rainfall at the closest reanalysis grid point 
lation between observed and reanalysed rainfall can be either because the reanalyzed circulation agrees with the real circulation or because the parameterization of rainfall compensates the errors of the reanalyzed circulation. This second possibility should be quite remote, however. Fig. 3 shows the correlation maps between the averaged Northern Tanzanian rainfall and the reanalysed monthly precipitation fields for the MM season. It can be seen that the correlation coefficients are highest in the location of the stations and attain values of the order of 0.6 in March, which indicate a reasonable representation of the true atmospheric circulation. In April the correlations are somewhat lower, of the order of 0.3 over Northern Tanzania, and in May they reach about 0.4, although the highest correlations are found further south. These results indicate that deficiencies indeed exist in the representation of rainfall in the NCEP/NCAR Reanalysis, but in view of the local and convective character of tropical rainfall, these values seem perhaps reasonable.

To estimate the spatial coherence of the precipitation in Northern Tanzania, EOFs of the precipitation time

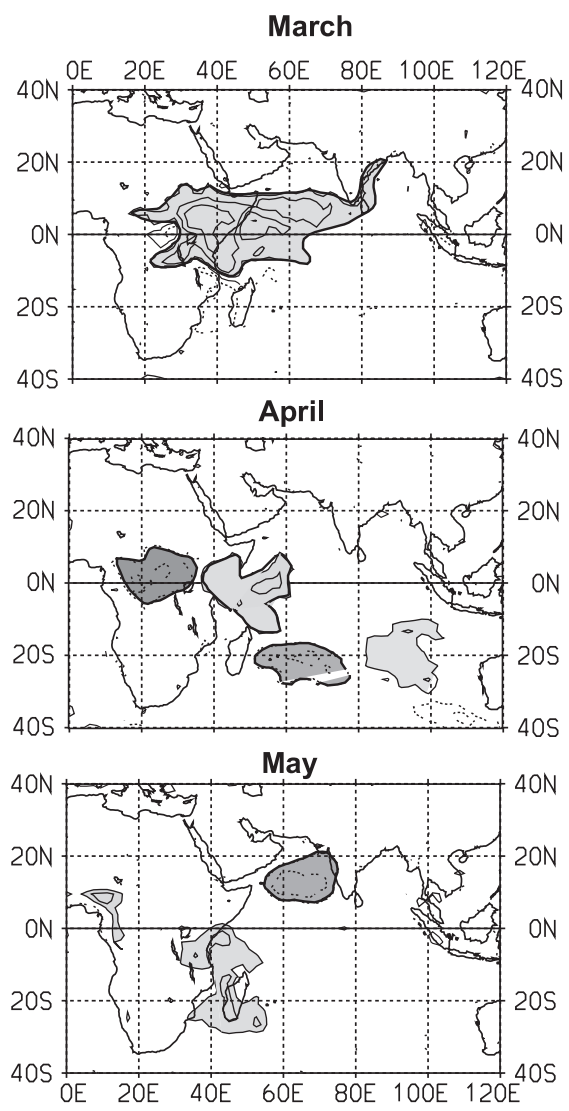

Fig. 3. Correlation maps between the averaged Northern Tanzanian rainfall and the monthly precipitation fields from the NCEP/NCAR Reanalysis. Isoline contour interval $=0.1$; dashed isolines: negative values. Light/dark shading: areas with correlations higher/lower than $0.2 /-0.2$
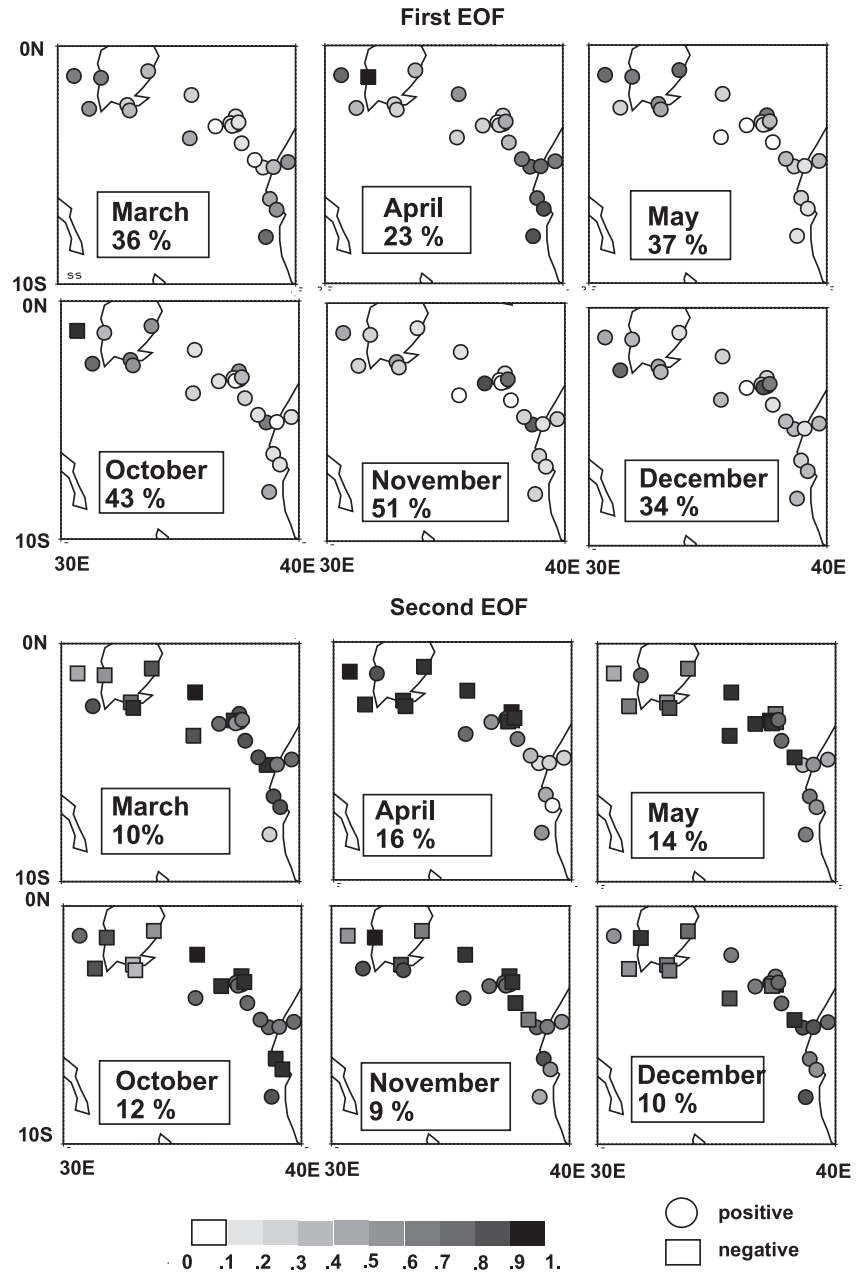

Fig. 4. The 2 leading empirical orthogonal functions (EOFs) of the standarized monthly precipitation for the rainy months in Northern Tanzania. Explained variances are also indicated

series were calculated separately for each month of the year. It can be seen (Fig. 4) that the spatial structures are very similar in all months for the first 2 leading EOFs. The leading EOF shows positive values at all stations, indicating that to the first order rainfall anomalies tend to be either positive or negative at all stations simultaneously. The second EOF shows positive values at the stations near the coast and negative at the stations located in the interior. The amount of variance explained by the leading EOF, a measure of the spatial coherence of precipitation, does not follow a clear pattern throughout the year.

A clearly different behavior between the MM and OD precipitation is the intraseasonal persistence of the precipitation anomalies. Table 2 gives the 1 mo lag time correlation of the 2 leading principal components. In the OD season these correlations are clearly higher, indicating that the precipitation anomalies tend to the 
same sign throughout the season. In the MM season the correlations are closer to zero. This could suggest that the OD precipitation is linked to lower-frequency processes than the MM precipitation. As stated in Section 1, the OD precipitation is probably involved in a coupled ocean-atmosphere variability mode in the Indian Ocean, and it would seem plausible that the whole season, and not individual months, is affected by these processes. In fact, a statistical prediction scheme for the OD precipitation based on wind indices in the Indian Ocean and the ENSO phase has been successfully developed (Kabanda \& Jury 1999).

This assumption is supported by Fig. 5, which shows the correlation maps between the leading rainfall principal component and the near-surface temperature field in the Indian Ocean-African sector. It can be seen that the temperature patterns associated with abovenormal rainfall are very stable in the OD season, with a warmer than normal Indian Ocean. In October and November the near-surface temperature patterns closely resemble the 'horse-shoe' signal found in the
Table 2. Time correlations between the leading principal components of Northern Tanzania precipitation calculated for each pair of months separately. The corresponding spatial structures are shown in Fig. 4. Note the high persistence of the first EOF in the October-December season

\begin{tabular}{|lrrrrrr|}
\hline & $\begin{array}{c}\text { Mar } \\
\text { Apr }\end{array}$ & $\begin{array}{c}\text { Apr } \\
\text { May }\end{array}$ & $\begin{array}{c}\text { Mar } \\
\text { May }\end{array}$ & $\begin{array}{r}\text { Oct } \\
\text { Nov }\end{array}$ & $\begin{array}{r}\text { Nov } \\
\text { Dec }\end{array}$ & $\begin{array}{r}\text { Oct } \\
\text { Dec }\end{array}$ \\
\hline EOF 1 & 0.24 & -0.22 & -0.26 & 0.56 & 0.48 & 0.42 \\
EOF 2 & 0.22 & 0.09 & -0.1 & -0.21 & -0.04 & 0.24 \\
\hline
\end{tabular}

Table 3. Correlations between the 2 leading EOFs of precipitation in Northern Tanzania for the March-May season and the all-India rainfall index (AIRI). See also Fig. 6

\begin{tabular}{|lrrr|} 
& Mar & Apr & May \\
\hline EOF 1 & 0.17 & 0.14 & -0.44 \\
EOF 2 & -0.14 & -0.17 & -0.32 \\
\hline
\end{tabular}
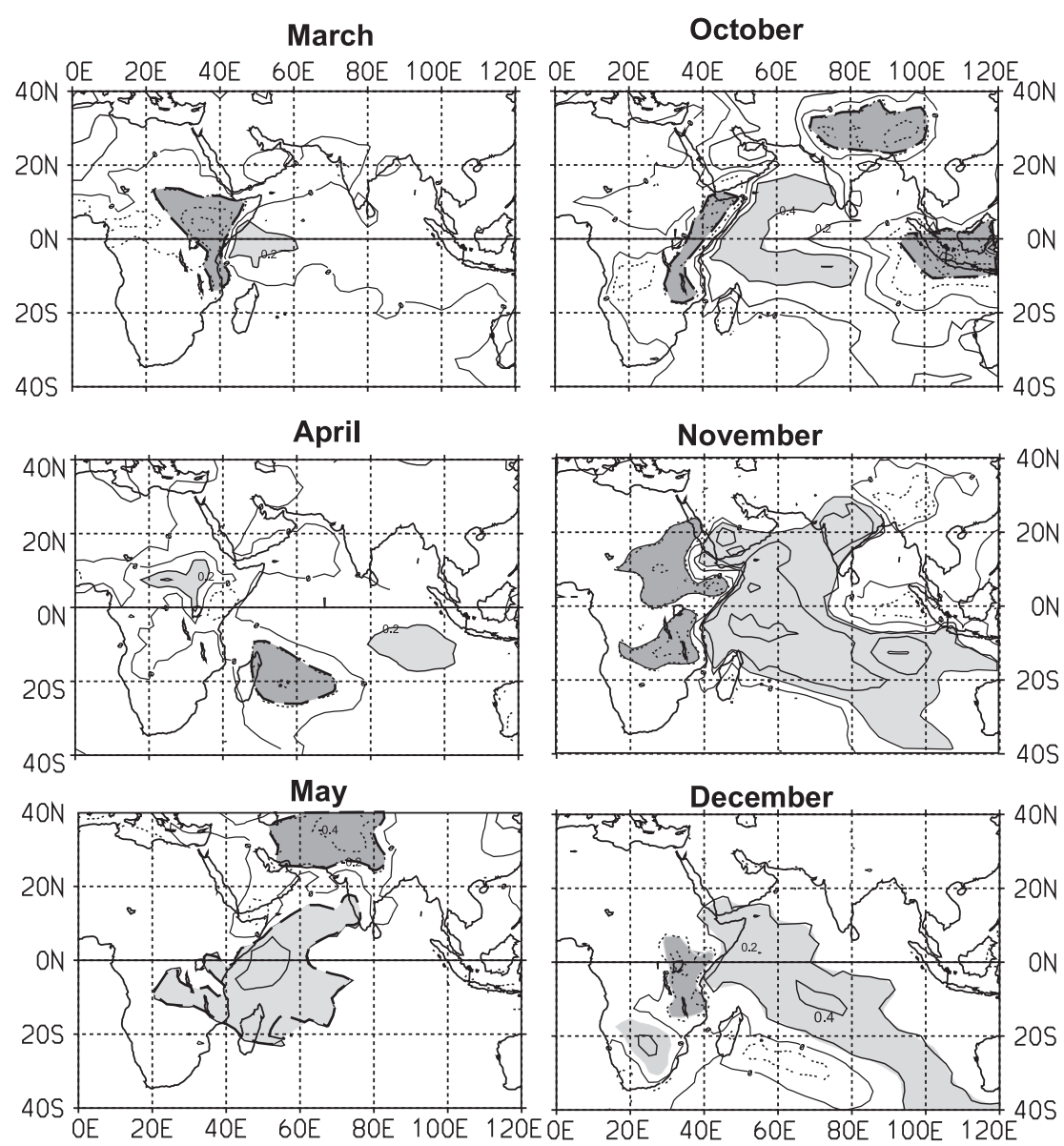

Fig. 5. Correlation maps between the leading EOF of Northern Tanzanian rainfall and the near-surface temperature field. Isolines and shading as in Fig. 3
SST field by Mutai \& Ward (2000). On the other hand, the associated temperature patterns in the MM season are much more different from one another. For instance, the temperature gradient in May is meridionally oriented, whereas in March and April it tends to be zonally oriented. Therefore, it seems justified to separate the study of rainfall variability in the 2 seasons. In this paper we will try to identify the large-scale patterns associated with rainfall in the MM season. A similar study of the OD season will probably have to take into account the recent work on the Indian Ocean 'ENSO-like' phenomenon (Webster et al. 1999).

A relevant question for the MM precipitation in Northern Tanzania is whether there exists any connection to the Indian Monsoon season, with an onset usually in June. Table 3 shows the correlation coefficients between the leading EOFs in each month of the MM season and the all-India rainfall index (AIRI, Sontakke et al. 1993). This index represents a spatial average of rainfall in the months June-August in the Indian subcontinent. Especially interesting is the relatively high correlation between the 


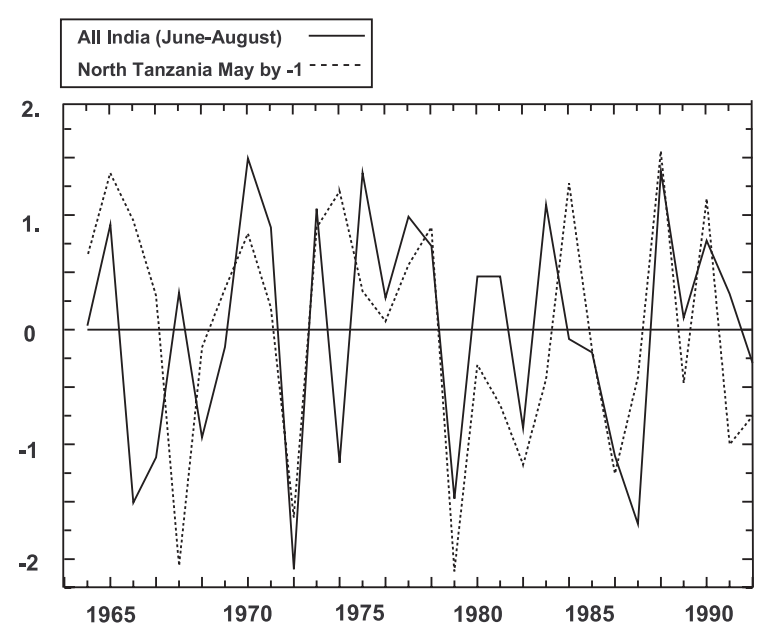

Fig. 6. Standarized time series of the all-India rainfall index (AIRI) and the leading EOF of Northern Tanzanian precipitation in May multiplied by -1

leading EOF of the Northern Tanzanian precipitation in May and the subsequent monsoon rainfall in India, a relationship that could in principle be used in a statistical prediction scheme of the Indian Monsoon (Fig. 6). This link will be addressed later. The months March and April do not show a link with the Indian Monsoon. These results point again to the lack of common sources for the MM precipitation variability.

\section{RELATIONSHIP BETWEEN THE NORTHERN TANZANIAN MARCH-MAY RAINFALL AND LARGE-SCALE VARIABLES}

In this section the statistical relationships between monthly precipitation in Northern Tanzania in the MM season and concurrent large-scale fields from the NCEP/NCAR Reanalysis are presented. Essentially, correlation maps between the 2 leading principal components of precipitation and the large-scale fields were calculated. The sign of the principal components corresponds to the structures shown in Fig. 4 , i.e. positive rainfall anomalies at all stations in the first EOF, and positive anomalies at the coast and negative anomalies in the interior in the second EOF. Due to the potentially important association between May rainfall and the Indian Monsoon, results for May are presented first.

\subsection{May rainfall}

The correlation between the leading EOF of May rainfall and the large-scale climate fields is shown in Fig. 7. Associated with increased rainfall at all stations simultaneously is a meridional air-temperature contrast between a warmer Indian Ocean and tropical African continent on one side and a cooler Asian continent on the other side. Simultaneously, north-easterly wind anomalies at the surface along the equatorial East African coast and south-westerly wind anomalies at $200 \mathrm{mb}$ height are observed. These anomaly fields are consistent with the close association between rainfall in May and the Indian Monsoon rainfall described by the AIRI: warmer Indian SSTs give rise to a weaker monsoonal circulation in May that is connected to moisture advection anomalies from the Indian Ocean into the African continent. At $200 \mathrm{mb}$ the opposite circulation is found. The loadings of the leading rainfall EOF are strong at the coastal stations and become weaker at the stations located in the interior, being quite weak at the stations around Lake Victoria. This result is confirmed by calculating the local correlations between AIRI and rainfall at each station (not shown).

The second rainfall EOF describes positive anomalies at the coastal stations and simultaneous negative anomalies in the interior. Associated to this anomaly dipole
Fig. 7. Large-scale correlation fields associated with the leading EOF of Northern Tanzanian rainfall in May. Isolines and shading as in Fig. 3. Only arrows larger than 0.4 are shown 


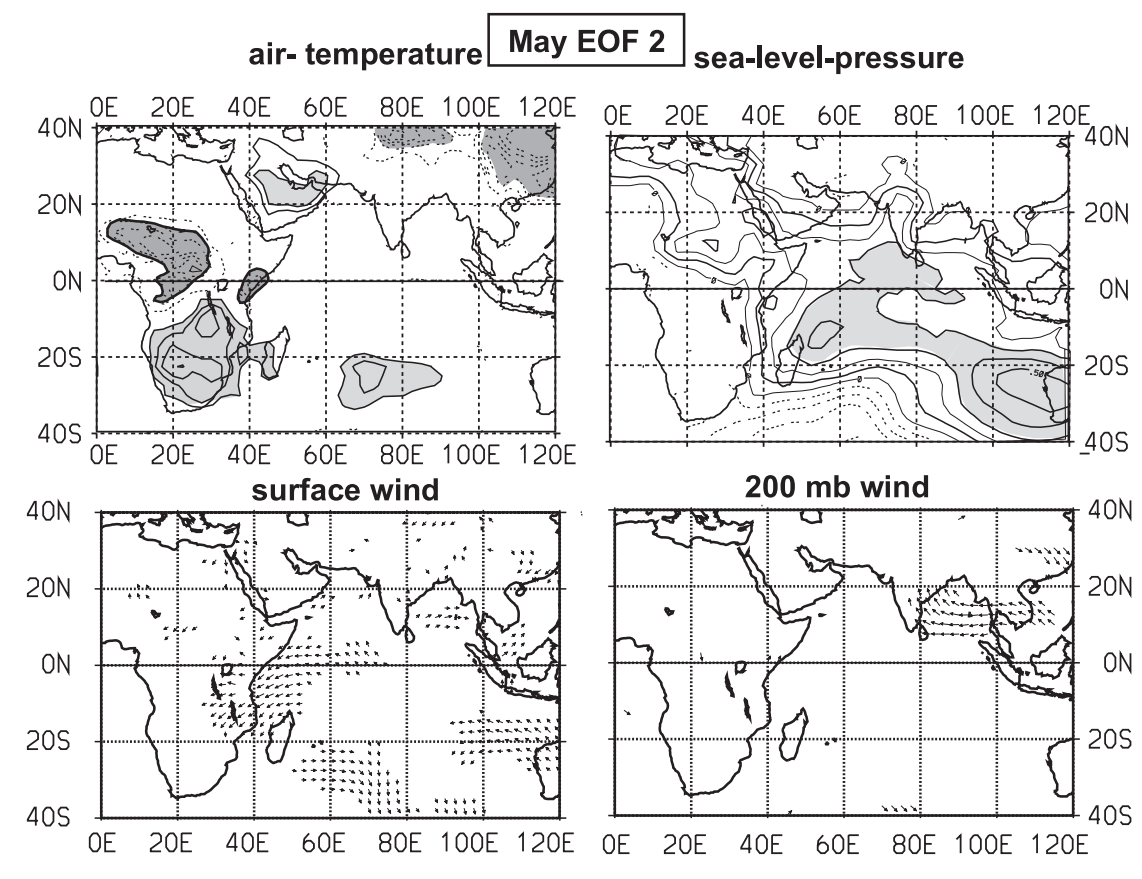

Fig. 8. Large-scale correlation fields associated with the second EOF of Northern Tanzanian rainfall in May. Isolines, shading and arrows as in Figs 3 \& 7
The surface wind and surface temperature patterns associated with the leading EOF of April rainfall are quite different to those for May. The surface temperature pattern in April shows a warmer than normal Indian Ocean and a cooler than normal African land mass. A small-scale structure is also observed in the vicinity of the Tanzanian stations and Lake Victoria. The SLP anomalies are weak, but the pattern shows consistent negative pressure values over the whole Indian Ocean. The surface-wind pattern indicates westerly anomalies along the equator and no link is found to the winds at the $200 \mathrm{mb}$ level. The westerly surface wind anomalies along the equator should be associated with convergence and upward velocities, due to the different sign of the Coriolis parameter on the 2 sides of the equator. This is also seen in the correlation map of the leading rainfall EOF and the vertical velocity at the $850 \mathrm{mb}$ level from the NCEP Reanalysis, as discussed in Section 5. The correlation with the vertical velocities are strongest over the Tanzanian stations and only in a quite limited area.

The second rainfall EOF (positive rainfall anomalies along the coast and negative anomalies in the interior) is associated with a near-surface temperature contrast in equatorial Africa between the northern and southern tropics. The near-surface winds blow across the equator northwards over Lake Victoria and inshore from the Indian Ocean at the coast. The SLP anomalies are slightly negative over the warmer regions north of the equator. The associated winds at $200 \mathrm{mb}$ are directed southwards over this region. A consistent interpretation of these results would suggest a quite short-scale anomalous circulation cell meridionally oriented, with an ascending branch over the warmer than normal Ethiopian High Lands (about $8^{\circ} \mathrm{N}, 35^{\circ} \mathrm{W}$ ) and a descending branch slightly south of the equator. This circulation would inhibit convection in the stations situated in the interior near Lake Victoria but would bring more humid air from the Indian Ocean to the coastal stations. The topographic profile around Mount Kilimanjaro would separate the 2 regions of influence.

\subsection{March rainfall}

The surface-temperature pattern associated with the leading rainfall EOF in March (Fig. 9) has characteris-
The large-scale climate anomalies associated with Tanzanian rainfall in April show a different character than in May. The signals are also much weaker than in May and March, and its interpretation is therefore more speculative. Perhaps April represents a transition month between the March regime and the May regime. The results for April will be just briefly described; they are not illustrated with diagrams. 


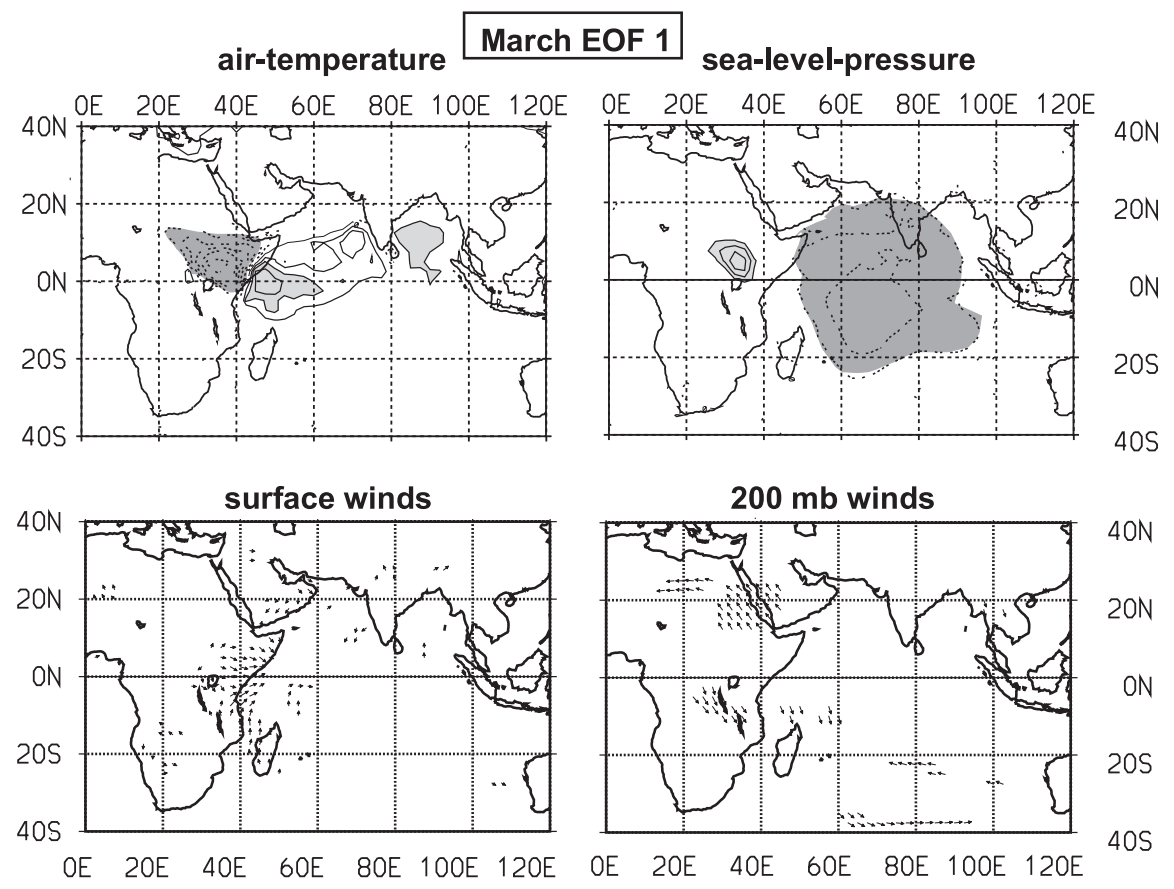

Fig. 9. Large-scale correlation fields associated with the leading EOF of Northern Tanzanian rainfall in March. Isolines, shading and arrows as in Figs 3 \& 7

with sinking air over the African land mass and rising humid air over the equatorial Indian Ocean that gives rise to positive rainfall anomalies predominantly at the coastal stations (which dominate the leading rainfall EOF). Recently, Hastenrath (2000) analyzed the zonal circulation over the Indian Ocean in the NCEP Reanalyses and concluded that a basin-wide Walker circulation spanning Indonesia and Eastern Africa is only established in the OD season. Our results may indicate that an anomalous zonal circulation is indeed responsible for rainfall anomalies, although they also show that the scale of this circulation is limited to the contrast between continent and ocean and is not basin-wide.

The second EOF of March rainfall is associated with warmer than normal temperatures over all Northern Tanzanian stations and cooler than normal near-surface temperatures over most

tics similar to the April pattern and also shows a zonal temperature gradient, but the signal is stronger. This is reflected also in the moderately positive correlation between the leading principal components in March and April (0.24, see Table 2). The near-surface temperature shows a relatively localized contrast between a warmer than normal western Indian Ocean and a cooler African land mass along the equator. The surface wind anomalies in Northern Tanzania have a westerly component. The SLP anomaly pattern shows lower pressure over the western Indian Ocean and higher pressures over equatorial Eastern Africa. At the $200 \mathrm{mb}$ level anomalous wind divergence towards the northwest and southeast is observed.

The westerly surface wind anomalies along the equator are, as in April, associated with convergence and upward velocities, due to the change in sign of the Coriolis parameter (see Section 5). The area of high correlations is again limited to the Tanzanian stations. At the $200 \mathrm{mb}$ level anomalous wind divergence towards the northwest and southeast is observed. These structures seem to indicate the existence of a zonal circulation cell, of the Indian Ocean (Fig. 10). This temperature pattern shows weakly the same horse-shoe fingerprint (with opposite polarity) as the temperature pattern in November. However, the associated patterns for all

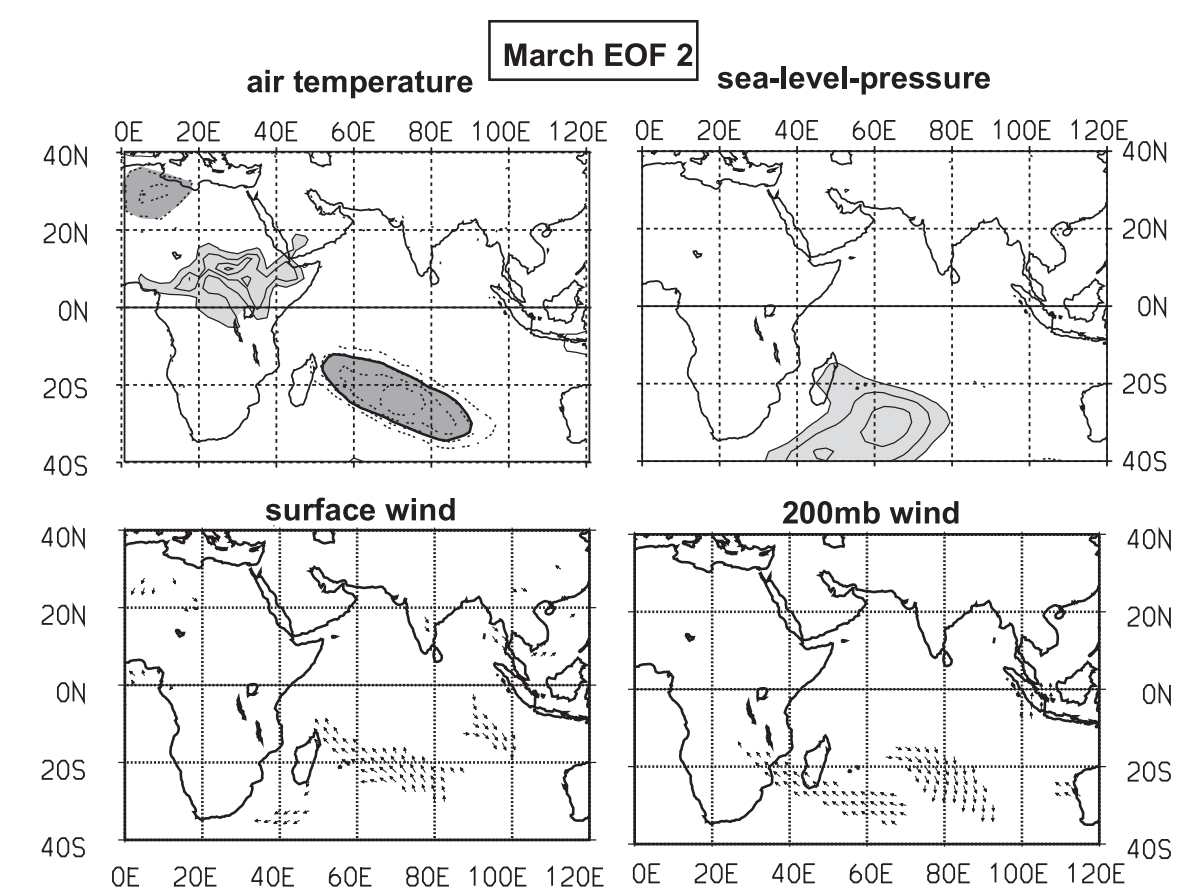

Fig. 10. Large-scale correlation fields associated with the second EOF of Northern Tanzanian rainfall in March. Isolines, shading and arrows as in Figs 3 \& 7 
other large-scale variables do not show a clearly interpretable picture: SLP is mostly above normal for the entire region, with only lower than normal values southeast of Madagascar, and the wind patterns do not indicate any structure that could be potentially relevant for the Northern Tanzanian stations. This second March EOF describes about $10 \%$ of the total variance, the lowest for all of the rainy months; perhaps the associated principal component is too contaminated by background noise. At this point no further interpretation seems reasonable to us.

\section{DISCUSSION}

The results indicate that the sources of interannual rainfall variability through the MM rainy season in Northern Tanzania differ from month to month. In March and April a zonal surface temperature gradient between Eastern Equatorial Africa and the Western Indian Ocean is associated with near-surface westerly winds anomalies. These wind anomalies induce convergence along the equator and promoting rising air motions in the considered area. Since rainfall in March is only weakly correlated with rainfall in the following April (Table 2), this temperature contrast has a relatively short autocorrelation time. Probably the short memory of the surface temperature anomalies over land is responsible for this lack of month-to-month rainfall correlation, since surface temperatures in the Western Indian Ocean should have a decay time longer than a month.

The near-surface temperature pattern in May is quite different. The temperature gradient is meridional, instead of zonal, and the SLP anomalies and surface-wind anomalies indicate a monsoon-like circulation directed towards equatorial Eastern Africa. It is very likely that this temperature gradient is persistent enough to drive in part the intensity of the following monsoon rainfall in India (Fig. 6). A reasonable interpretation of these results could be that in March the intensity of low-level convergence is modulated locally by the zonal temperature gradient along the equator, whereas in May the anomalous monsoon forcing is already strong enough to influence precipitation totals through moisture advection.

In a recent work focused on Eastern African precipitation in the OD season, Mutai \& Ward (2000) also discuss briefly the differences in the forcing mechanisms of rainfall in the MM and OD seasons. Contrary to the work of Saji et al. (1999), these authors proposed that the OD rainfall is linked to some extent to ENSO. Based on the similarities of the associated SST pattern of May rainfall and OD rainfall, these authors suggest that the character of May rainfall is more closely asso-

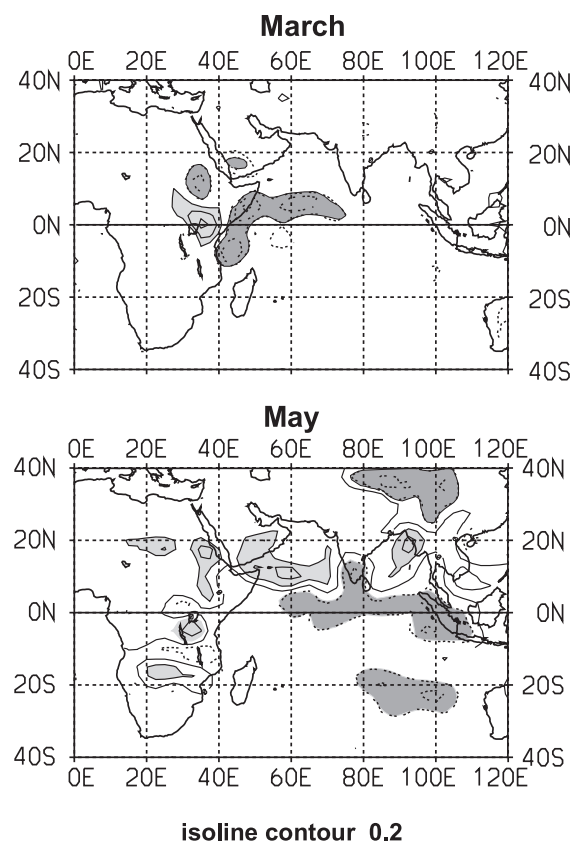

Fig. 11. Large-scale correlation fields between the leading EOF of Northern Tanzanian rainfall and the vertical velocity at the $850 \mathrm{mb}$ level in the March-May season. Isolines and shading as in Fig. 3, except contour interval $=0.2$

ciated with the OD rainfall and hence to ENSO. It should also be mentioned that Latif et al. (2000) found in an experiment with a general circulation model forced by the SST anomalies in the Indian Ocean observed in December-January 1997/1998 that simulated Eastern African rainfall was caused by the Indian Ocean temperatures and not by the Pacific Ocean temperatures.

Our results indicate a close link between May rainfall and the Indian Monsoon. The connection between the Indian Monsoon and ENSO is still a matter of debate, and it might be that these 2 phenomena are to some extent related. At this point, in view of the correlation between May rainfall and the AIRI and the shorter distance to the Indian subcontinent than to the Tropical Pacific, it seems more natural to assume a closer relationship between Eastern African rainfall in May and the Indian Monsoon.

Fig. 11 shows the correlation patterns between the leading EOF of rainfall and the vertical velocity at the $850 \mathrm{mb}$ level from the NCEP/NCAR Reanalysis and supports this interpretation. In March and April the correlations with the vertical velocity are relatively high and positive over the Northern Tanzanian stations, indicating stronger than normal convective activity. On the other hand, in May the area of positive correlations is smaller and actually the correlation is negative over the Tanzanian stations. This may be a consequence of the relatively weak relationship be- 
tween the station rainfall and the reanalysed rainfall, i.e. the reanalysed circulation may not be representing well the true circulation anomalies, but a reasonable interpretation could also be that the rainfall anomalies in May are actually connected not primarily to convergence anomalies but to large-scale humidity advection by the monsoon forcing. The correlation pattern between station rainfall and surface winds in May (Fig. 7) would support this interpretation.

Despite this different behavior, the spatial coherence of the rainfall field, indicated by the EOF structures shown in Fig. 4, is fairly similar in all months, including those of the OD season, which definitively show quite different temporal characteristics. The variances explained by the leading EOFs do vary throughout the year but the leading EOF always describes rainfall anomalies of the same sign in all stations and the second EOF is associated with the rainfall contrast between the coast and the stations in the interior. This fact is quite remarkable, and it is noted that the complicated orography in this region may be the source of these quite stable relationships among the different stations reflected in the EOF patterns.

The picture that emerges from these results is that rainfall anomalies in the MM season are caused by a quite different process. This conclusion should be quite relevant for statistical prediction schemes on seasonal time scales, a topic of considerable interest for areas where agriculture plays the most important economic role. In that context, the importance of timing of rainfall anomalies for agricultural activities will have to be defined a priori, and a prediction scheme should be focused on the time span within the season most important for agriculture. This study has analysed monthly rainfall totals, but quite probably the transition from the zonally dominated rainfall in March to the meridionally forced rainfall in May should be smooth in time. A prediction scheme would have then to be focused in time scales shorter than monthly, if data are available with enough time resolution.

On the other hand, May rainfall anomalies in Northern Tanzania seem to be a good predictor for monsoon rainfall. Obviously, rainfall data can be prepared and analysed much more rapidly than SST data, on which the current prediction schemes are mostly based (Clark et al. 2000). The possibility of using rainfall data along the East African coast, and not only from Tanzania, for a monsoon prediction scheme is worth exploring.

Editorial responsibility: Hans von Storch, Geesthacht, Germany
Acknowledgements. We thank the members of the Reanalysis Project of the National Center for Environmental Prediction for making available the very useful reanalysis data to the whole scientific community. We are also grateful to 3 anonymous reviewers, who greatly contributed to the improvement of this manuscript.

\section{LITERATURE CITED}

Clark CO, Cole JE, Webster PJ (2000) Indian Ocean SST and Indian summer rainfall: predictive relationships and their decadal variability. J Clim 13:2503-2519

Hastenrath S (2000) Zonal circulations over the equatorial Indian Ocean. J Clim 13:2746-2756

Hastenrath S, Nicklis A, Greischar L (1993) Atmospheric and hydrospheric mechanism of climate anomalies in the western equatorial Indian Ocean. J Geophys Res 98: 20219-20235

Janowiak J, Grubber A, Kondeagunta CR, Livezey R, Huffmann G (1998) A comparison of the NCEP/NCAR reanalysis precipitation and the GPCP raingauge-satellite combined datasets with the observational error considerations. J Clim 11:2960-2979

Kabanda TA, Jury MR (1999) Interannual variability of short rains over Northern Tanzania. Clim Res 13:231-241

Kalnay E, Kanamitsu M, Kistler R, Collins W, Deaven D, Gandin L, Iredell M, Saha S, White G, Woollen J, Zhu Y, Chelliah M, Ebisuzaki W, Higgins W, Janowiak J, Mo KC, Ropelewski C, Wang J, Leetmaa A, Reynolds R, Jenne R, Joseph D (1996) The NCEP/NCAR 40-year reanalysis project. Bull Am Meteorol Soc 77:437-471

Kerr RA (1998) Climate prediction-models win big in forecasting El Niño. Science 280:522-523

Latif M, Dommenget D, Dima M, Grötzner A (2000) The role of Indian Ocean sea surface temperature in forcing East Africa rainfall anomalies during December-January 1997/98. J Clim 12:3497-3504

Meehl GA (1997) The south Asia monsoon and the tropospheric biennial oscillation. J Clim 10:1921-1943

Mutai CC, Ward MN (2000) East African rainfall and the tropical circulation/convection on intraseasonal to interannual time scales. J Clim 13:3915-3939

Poccard I, Jannicot S Camberlin P (2000) Comparison of rainfall structures between NCEP/NCAR reanalysis and observed data over Tropical Africa. Clim Dyn 16:897-915

Saji NH, Goswanni BN, Vinayachandran PN, Yamagata T (1999) A dipole mode on the tropical Indian ocean. Nature 401:360-363

Sontakke NA, Pant GB, Singh N (1993) Construction of allIndia summer monsoon rainfall series for the period 1844-1991. J Clim 6:1807-1811

von Storch H, Zwiers F (1999) Statistical analysis in climate research. Cambridge University Press, Cambridge

Webster PJ, Moore AM, Loschnigg JP, Leben RR (1999) Coupled ocean-atmosphere dynamics in the Indian Ocean during 1997-98. Nature 401:356-360

Submitted: February 11, 2001; Accepted: July 9, 2001

Proofs received from author(s): December 18, 2001 